DOI: $10.26907 / 2074-0239-2019-57-3-58-64$

УДК 801.37

\author{
ПАРЕМИИ КАК ТРАНСЛЯТОРЫ \\ КОНСТАНТНОГО ЯЗЫКОВОГО СОЗНАНИЯ
}

\author{
(C) Лилия Касерта
}

\title{
PAREMIAS AS TRANSLATORS OF CONSTANT LINGUISTIC CONSCIOUSNESS
}

\begin{abstract}
Lilia Caserta
The article explores the role of Russian, American and Mexican paremias as linguistic constants and representatives of linguistic consciousness. By analyzing paremias about language and speech in Russian, American English and Mexican Spanish languages, we demonstrate differences and similarities in national systems of values and unique ways of interpreting world knowledge in each language. The purpose of the research is to identify national interpretations of worldviews and philosophies of life using a cognitive-pragmatic analysis of proverbs. The object of our study is paremias about language and speech in Russian, American English and Mexican Spanish languages. We explore the relationships between language, understanding of the world and national mentality. The analysis of paremias from three different languages makes it possible to evaluate the role of national culture in representing reality and its influence on the linguistic expression of the world. Paremiological material illustrates people's collective historical experience, their national culture, expressed in language and reflected in speech. Thus, the study suggests the unique role of paremias as linguistic constants, representing linguistic consciousness in the process of international communication and understanding their national culture and worldview. The modal constant of paremias lies in its unconditional truth, which is proved by the authority of popular opinion.
\end{abstract}

Keywords: paremia, linguistic constant, linguistic consciousness, speech, language.

В статье рассматривается роль русских, американских и мексиканских паремий как трансляторов константного языкового сознания. Анализ паремий о языке и речи в русском, американском английском и мексиканском испанском языках демонстрирует различия и сходства национальной системы ценностей и уникальность национального мировоззрения каждого народа. Цель исследования - определить национальную специфику миропонимания и жизненной философии каждой нации с помощью когнитивно-прагматического анализа пословиц. Объектом нашего изучения являются паремии русского, американского английского и мексиканского языков, репрезентирующих концепт «Язык - Речь», которые рассматриваются как сжатые тексты, отражающие функции и роль речи, характерные для каждого народа. Анализ пословиц трех сопоставляемых языков позволяет определить роль национального менталитета и его влияние на языковое выражение окружающего мира. Паремиологический материал иллюстрирует коллективный исторический опыт народа, его национальную культуру, выраженную в языке и отразившуюся в речи. Таким образом, исследование позволяет сделать вывод об уникальной роли паремий как трансляторов константного языкового сознания в процессе международной коммуникации и понимания национальной культуры и мировоззрения. Модальная константа паремий заключается в ее безусловной истинности, которая доказана авторитетом народного мнения.

Ключевые слова: паремия, лингвистическая константа, транслятор константного языкового сознания, речь, язык.

Современное языкознание исследует взаимосвязь языка и народного менталитета. Изучение паремий как культурных «кодов» языковой картины мира разных наций позволяет выявить схожие и различные представления об окружающей действительности. Целью настоящего исследования является выявление национально-специфи- ческих черт паремий, репрезентирующих концепт «Язык - Речь» в русском, американском английском и мексиканском испанском языках.

Сопоставительный анализ пословиц русского, американского английского и мексиканского испанского языков позволяет выделить общие и различные представления о мире, отраженные в языке. 
Изучением проблемы взаимосвязи и взаимодействия языка и культуры занимались многие исследователи. Известные ученые В. фон Гумбольдт, К. Фосслер, А.А. Потебня, Э. Сепир исследовали язык как культурный «код» нации, как отражение народной культуры. Лингвист В. фон Гумбольдт в статье «Лаций и Эллада» (1806 г.) писал: «Всякое изучение национального своеобразия, не использующее язык как вспомогательное средство, было бы напрасным, поскольку только в языке запечатлен весь национальный характер» [Гумбольдт, «Лаций и Эллада», с. 303]. Он сформулировал положение о связи языка и народного характера, национальной культуры в работе «О различии строения человеческих языков и его влиянии на духовное развитие человеческого рода» [Гумбольдт, «О различии....»]. Согласно лингвистической теории В. фон Гумбольдта, язык является неотъемлемой частью народной культуры, «народным духом». А. А. Потебня развил идеи В. фон Гумбольдта в исследовании «Мысль и язык» (1862 г.): «Принявши... дух в смысле сознательной умственной деятельности, предполагающей понятия, которые образуются только посредствам слова, мы увидим, что дух без языка невозможен, потому что сам образуется при помощи языка, и язык в нем есть первое во времени событие» [Потебня, c. 37]. Американский ученый Э. Сепир в монографии «Language: An Introduction to the Study of Speech» (1921 г.) утверждает, что язык является «руководством к восприятию социальной действительности» [Сепир, с. 185]. Исследователь определяет взаимосвязь языка и культуры следующим образом: «Язык не существует вне культуры, то есть вне социально-унаследованной совокупности практических навыков и идей, характеризующих наш образ жизни» [Там же]. Язык, его грамматический строй, лексика и фразеология являются неким кодом, который определяет своей структурой уникальность языкового сознания. Лингвисты П. Я. Гальперин и О.Я. Кабанова в исследовании «Языковое сознание как основа формирования речи на иностранном языке» утверждают, что «языковое сознание - это закрепленный в грамматических значениях специфический языковой способ отражения действительности народом, говорящим на данном языке» [Гальперин, Кабанова, с. 111]. Исследователь Е. Ф. Нечаева в статье «Языковое сознание и менталитет» описывает схему взаимоотношений языка, языкового сознания и национального менталитета следующим образом: язык формирует языковое сознание; языковое сознание, в свою очередь, является инструментом в формировании национального менталитет [Нечаева, с. 31].
Языковое сознание народа отражает национальные быт, историю, культуру, традиции и обычаи. Паремии являются отражением коллективного опыта и знания нации. Пословица представляет собой сложную языковую единицу. Паремиологический материал является объектом изучения нескольких наук: лингвистики, фольклористики, психологии, этнографии и других. Исследователи рассматривают паремию как суждение, содержащее в концентрированной форме многовековой опыт народа. Например, ученый Ф. И. Буслаев определяет пословицы как «художественные произведения родного слова, выражающие быт народа, его здравый смысл и нравственные интересы» [Буслаев, с. 4]. Исследователь Г. Л. Пермяков утверждает, что «пословицы выражают определенную закономерность, которая может быть воспринята как постоянное правило, обычай, своего рода рекомендация для всех и каждого» [Пермяков, с. 16]. Американский ученый Ш. Арора утверждает, что пословица «это голос древней культуры, вещающий абсолютную истину» [Arora, c. 24]. Исследователифольклористы выделяют следующие черты пословицы: народность, образность, краткость, назидательность.

Лингвокультурология изучает паремии как культурную ценность, как отражение национальной системы ценностей. Исследователилингвокультурологи И. Р. Гальперин, А. В. Кунин, Ю. А. Сорокин, А. Е. Супрун определяют паремию как лингвокультурный текст, который в концентрированном виде отражает народное мировосприятие, характеризует важные исторические события, демонстрирует традиции, нравы, обычаи носителей языка. Лингвокультура исследует культурно-языковые характеристики пословиц, которые, в свою очередь, отражают национальную специфику восприятия мира. Таким образом, мы утверждаем, что паремии являются неотъемлемой частью любого языка и национальной культуры; отражением народной жизни, языковой иллюстрацией образа мыслей и национального характера. Устойчивые языковые единицы демонстрируют пересечение языковой системы и социального контекста. В паремиях выражаются народные культурные нормы, мораль, предлагаются модели поведения.

Паремия является объектом когнитивных исследований, которые изучают механизмы переработки информации об окружающем мире человеческим сознанием. Когнитивный подход в изучении паремии позволяет рассматривать пословицу как разновидность культурных аксиомутверждений, абстрактных структур сознания. Отличительной особенностью устойчивых язы- 
ковых выражений является их исконно национальное происхождение, это явление можно проследить на основе использования географических названий, исторических событий и бытовых деталей для создания устойчивых языковых выражений. Топонимы, антропонимы, историзмы являются национально-культурным компонентом и выражают национальную самобытность. Например, исконно русская пословица Язык до Киева доведет [Снегирёв, с. 147], имеющая значение «узнать необходимую информацию», ссылается на город Киев - столицу Древней Руси как на столицу славянского мира, культурный, экономический и политический центр страны. Таким образом, данная паремия передает ясную для русского человека информацию, в то же время иностранцу необходимо дополнительное разъяснение смысла пословицы для адекватного восприятия и употребления этого выражения в речи. Американская паремия Fine words butter no parsnips [Fergusson, с. 232] - 'Красивые слова пастернак не маслят' (здесь и далее перевод наш - Л.К.) использует название местного овоща пастернак, который традиционно готовится с маслом. Значение американской паремии - «пустые слова не имеют веса» - не связано с кулинарией, однако использование бытовой метафоры позволяет образно передать смысл паремии. Не американцу эта пословица может быть непонятна, и употребление паремии в речи может привести к проблемам в коммуникации. Национально-культурный компонент выражается в употреблении бытовых реалий, например, русских слов самовар, решето, лапти или в буквальном прочтении языковых выражений: tongue run away with thy brains [Там же, с. 231] - 'язык сбежал с мозгами', much babbling is not without offence [Там же] - 'нудное бормотание обижает / раздражает'. Использование имен собственных из фольклорного и исторического материала так же является национально-культурным компонентом. Например, мексиканская паремия Habla Beltrán, y habla por su mal [Junceda, c. 266] - 'Говори o Белтране, говори и его проступках' использует имя фольклорного персонажа в тексте. Таким образом, можно утверждать, что паремии отражают определенное видение мира, закрепленное с помощью языковой единицы, выражают национально-культурный опыт народа.

Национальный менталитет и народная культура являются уникальными по своей природе явлениями: с одной стороны, они национальноспецифичны, с другой - они универсальны и интернациональны. Подтверждением этой двойственной природы паремиологического материала являются примеры схожих по своему значению и выражению паремий в различных языках. Например, русская паремия $У$ семи нянек дитя без глазу [Жуков, с. 401] имеет эквивалент в американском английском языке: Too many cooks spoil the broth - 'Чрезмерное количество (множество) поваров портит бульон' [Mieder, с. 116]. Мексиканцы выражают эту мысль с помощью паремии Junta de pastores, chivo muerto - 'У coвеma (груnnы) пастухов коза мертвая' [Pérez Martínez, c. 262]. Данные паремии имеют сходное значение «множество не равносильно высокому качеству», однако этот смысл выражен с помощью национальных образов: няня, бульон и пастухи.

Использование пословиц и поговорок в речи даёт возможность обобщать знания и одновременно оценить явление или поведение. Речевой акт, как социальный и коммуникативный процесс, направлен на получение информации и обмен ею, коммуникацию, воздействие на слушателя, побуждение к действию и т. д. Его целью является успешное воздействие на коммуникативного партнера. Согласно теории речевых актов, паремии выполняют в языке функции совета, рекомендации, запрета и т. д. Таким образом, паремиологическое высказывание как особая единица языка представляет собой воспроизводимый в речи оборот воздействующего характера, который в своем содержании вербализует стереотипные представления народа.

Сопоставление паремиологического материала трех языков позволяет нам выявить существующие стереотипные речевые ситуации и их реализацию, характерные для каждого народа. Когнитивно-прагматический анализ русских, американских и мексиканских паремий как трансляторов константного языкового сознания на примере пословиц группы «Речь - Язык» в словарях В.И. Даля, И. В. Снегирёва, В. И. Зимина, В. П. Аникина, В. Мидера, Р. Фергюссона, А. Лайна, Х. Перез-Мартинеса, М. Глайзера позволяет выделить основные лексемы, репрезентирующие концепт «Речь - Язык» в анализируемых лингвокультурах.

Паремия содержит определенную рекомендацию к действию. Наше исследование анализирует паремии речевого действия как возможные модели речевых ситуаций в русской, американском английском и мексиканском испанском языках. Сходные речевые ситуации имеют различные реализации, обусловленные национальным языковым менталитетом. Например, русские паремии описывают и критикуют неумелую речь, используя сравнение и метафору: Долго говорит - ум копит; а вымолвит - слушать нечего [Даль, с. 281]; У него слово слову костыль подаёт [Там же, с. 282]; Слово к слову приставляет, 
словно клетки городит [Там же]; Говорит, как сани по песку тащит [Зимин, с. 367]; Говорит, как будто три дня не ел [Там же]; Молоко скиснет, пока он слово вымолвит [Там же]; Слово насилу молвит, как будто язык киселем кормит [Снегирев, с. 280]; Говорит, как плохая плетея кружева плетет: что сплетет - ничего не разберет [Аникин, с. 64]; Говорит что плетень плетет' [Там же]. Анализ русских паремий позволяет утверждать, что когнитивный компонент иллюстрирует возможные модели действия: по песку тащить тяжело, молоко киснет в течение нескольких дней, костыль необходим для неспособного самостоятельно двигаться и т. д. Совокупность когнитивных компонентов русских паремий демонстрирует негативную оценку медлительной речи. Прагматический компонент выражается в отношении к ситуации, в паремиях данной группы - это отрицательное отношение, так как медленная речь ассоциируется с проблемными, трудоемкими житейскими ситуациями: городить клетки, не разобрать сплетенное кружево, плести плетень. Для русской лингвокультуры форма речи, умение говорить свободно, образно имеют большое значение, при этом содержание сказанного не всегда играет доминирующую роль в речевом процессе. Для русского менталитета умение говорить является полезным навыком. Русские паремии $У$ него язык хорошо подвешан [Зимин, с. 363]; Говорит как пишет, словно бисер нижет [Там же]; Недолго думал, да ладно молвил [Там же, с. 368] подтверждают это наблюдение. Речевой процесс для русского человека - это не просто средство для передачи информации, но и возможность продемонстрировать свои ораторские способности и интеллект. Русские паремии используют хорошо известные бытовые ситуации для образной передачи речевого действия и его оценки. Поэтому русские воспринимаются представителями иностранных культур как любители поговорить, которые охотно делятся личной информацией, с удовольствием обсуждают различные темы.

Американские паремии придают большое внимание не форме речи, а содержанию сказанного. Например: It's not what you said; it's what you didn't say [Mieder, c. 525] - 'Важно не то, что ты сказал, а то, что ты не произнёс'; It is not what you say, but how you say it [Там же] 'Важно не то, что ты сказал, а то, как ты сказал'; Say what you mean and mean what you say [Там же] - 'Говори, что думаешь и думай, что говоришь'; The more you say, the less you shine [Там же] - 'Чем больше вы говорите, тем меньше вы заметны'; Watch what you say, when, and to whom [Там же] - 'Следи, что ты говоришь, ко- гда и кому'; Sayins go cheap [Там же, с. 526] 'Разговоры задешево идуm'; Be silent if you have nothing worth saying [Там же] - 'Молчи, если тебе нечего сказать'; Big talking, but little saying [Там же] - 'Много говорено, мало сказано'; If it isn't worth saying, don't say it at all [Там же] - 'Если слово не достойно быть сказанным, не говори его вообще'; Talk good, talk on; talk bad, stop [Там же, с. 582] - 'Говоришь хорошее, продолжай, говоришь плохое, остановись'; One who talks the loudest says the least [Там же] -'Tom, кто громче всех говорит, говорит не по существу'. Американские паремии предпочитают использовать последовательность действия: если нечего сказать, то молчи, думай, прежде чем говорить, говори хорошее, не говори плохое и т. д. Таким образом, когнитивно-прагматический анализ американского паремиологического материала иллюстрирует практицизм как национальную специфику: разговор «дешев», говори немного, кратко. Так же уникальной национальной характеристикой является причинно-следственная зависимость речи и славы или возможности быть заметным - «to shine». Это типично американская черта, характерная для психологии «self made man» - 'самостоятельно созданного человека'. Анализ когнитивного компонента американских паремий позволяет утверждать, что для американской лингвокультуры важное значение имеют содержание сказанного, речевая ситуации и форма речи. Паремии, функционирующие как рекомендации к действию, могут иметь двойную интерпретацию. Например, паремия If it isn't worth saying, don't say it at all [Mieder, c. 526] 'Если слово не достойно быть сказанным, не говори его вообще' в определенной речевой ситуации может иметь смысл «говори содержательно и кратко» и так же может быть использована как рекомендация к молчанию в значении «предпочтительнее молчать, чем говорить». Анализ американских пословиц демонстрирует, что американцы предпочитают говорить немного, по существу и подкреплять сказанное действиями. Прагматический компонент их иллюстрирует важность правдивости и позитивного содержания сказанного, слова должны быть положительные. В речевом процессе не приветствуются пустословие и сплетни, подчеркивается важность краткости и содержания сказанного. Паремия $B y$ talking, people understand one another [Mieder, c. 582] - 'Благодаря речи люди понимают друг друга' определяет роль речевого процесса в американской национальной лингвокультуре; речь это средство успешной коммуникации. Американские пословицы рекомендуют определенную модель поведения для говорящего, функциони- 
руют как инструкции к действию. Для иностранцев американцы в процессе коммуникации воспринимаются как примеры положительного речевого поведения, они говорят сдержанно, позитивно, по существу, не обсуждают личные информацию, придерживаются схемы «сказано сделано». Поэтому в американской культуре существуют такие явления, как inspirational speech - вдохновляюшая риторика, motivational speaker - мотивачионный оратор, так как речевой процесс является не только средством коммуникации, но и мотивацией к активному действию.

Мексиканские паремии, репрезентирующие концепт «Речь - Язык», отражают национальный менталитет, объективизируют историческую и культурную специфику. Устойчивые языковые выражения иллюстрируют уникальное восприятие и оценку речи как социального явления в народной культуре. Пословицы функционируют как рекомендации к действию, возможные модели коммуникационного процесса. Паремии Habla siempre que debas, y calla siempre que puedas [Torres, c. 69] - 'Всегда говори, что должен, и всегда молчи о том, что ты можешь'; Más pronto cae un hablador que un cojo [Gómez de Silva, c. 88] - 'Быстрее упадёт говорящий, чем хромой'; Hablar poquito; y mear, clarito [Junceda, с. 267] - 'Говорить мало и быть здоровым' предостерегают говорящего, демонстрируют приоритет молчания. Паремия Hablar a tiempo require tiento [Там же] - 'Чтобы сказать вовремя / к месту необходима интуиция' акцентирует важность речевой ситуации, умение не только говорить содержательно, но и понимать уместность сказанного. Только в мексиканском паремиологичеком фонде мы нашли пример языкового выражения, который демонстрирует преимущество коллективной речи в сравнении с речью индивидуальной. Паремия Dicho de uno, dicho de ninquno [Junceda, c. 192] - 'Слова одного говорящего равносильны тишине / не существуют' объективизирует это явление. Когнитивнопрагматический анализ данной паремии демонстрирует несколько возможных интерпретаций. Первая интерпретация: речь говорящего без поддержки многих не имеет значения, при этом содержание и форма сказанного не важны, таким образом, подвергается сомнению индивидуализм как возможная модель социального поведения. Вторая интерпретация: коллективное мнение, невзирая на содержание, является доминирующим и приоритетным. Мексиканцу важно чувствовать социальную поддержку в речевом процессе, глубокая зависимость человека от общественного мнения характерна для агрокультурной общины, где главная характеристика - единство личности и социума. Для характеристики необдуманной речи, пустословия мексиканцы применяют паремию Hablar come papagayo [Junceda, c. 267] - 'Говорить как попугай', используя попугая как национально-культурную метафору. Паремии Hablar bien no cuesta dinero [Там же] 'Хорошие слова не стоят денег'; Hablar de la mar, y en elle no estar [Там же] - 'Говорить о море, ни разу не увидев его' ; Unos ho hablan lo quе piensan, y otros no piensan lo que hablan [PérezMartínez, c. 234] - 'Одни не говорят, что думают, другие не думают, что говорят'; Quien habla lo que no debe, oye lo que no quiere [Torres, c. 99] - 'Тот, кто говорит то, что не должен, усльишт, то, что не хочет' являются примерами универсальной природы речевого процесса. Так же, как русские и американские, мексиканские паремии предостерегают говорящего, советуют говорить немного и к месту, то есть заранее оценивать речевую ситуацию. Можно отметить, что мексиканские паремии не придают значения содержанию и форме речи в сравнении с американскими и русскими паремиями. Они акцентируют возможные последствия сказанного, ситуационную необходимость и поощряют сдержанность и немногословие. Для мексиканца сказанные слова опасны, а одинокий говорящий, без поддержки других, не имеет голоса, вообще не существует. Анализ паремий о языке и речи объясняет речевое поведение мексиканцев, которые воспринимаются иностранцами как сдержанные, скрытые и замкнутые.

Паремии, выполняя функцию трансляторов константного языкового сознания, являются рекомендациями к правилам общения и поведения. Например, русские паремии Хорошо говорит, а послушать нечего [Даль, с. 278]; И красно, и пестро (говорит), да пустоцветом [Там же, с. 279]; Говорил день до вечера, а слушать нечего [Аникин, с. 63]; Говорить без дела, что на воде писать [Там же, с. 64]; Пустые слова - что орехи без ядра [Там же, с. 269]; Пустое слово как солома, - много местом, да мало весом [Там же] являются речевыми актами декларации. Паремии русского языка демонстрируют важность содержательной речи, осуждают многословие. Национальным своеобразием русских паремий является использование ассоциативного действия: $n u$ сать на воде. Применение метафор пустой орех, пустая солома, пустоцвет, использующие основу пусто в значении «отсутствие», исконно русские. Похожие примеры в американском паремиологическом материале применяют иные способы выражения данного смысла. Например, пословицы Great talkers are like broken pitchers: everything runs out of them [Mieder, c. 582] - 'Be- 
ликие болтуны как разбитые горшки: всё из них вытекает'; He who talks mисh errs тисh [Там же, c. 581] - 'Кто много говорит, тот много ошибается'; Loose talk cost lives [Там же] - 'Пустой разговор / сплетня разрушает жизнь'; Не who gives fair words, feeds you with empty spoon [Lane, с. 232] - 'Кто говорит красивые слова, кормит пустой ложкой'. Ироничное использование описательных характеристик великие слова, красивые слова подчеркивает американский практицизм. Метафоры разбитый горшок, пустая лож$\kappa a$ обращаются к бытовым образам для описания результата речевого процесса. Мексиканские паремии так же отрицательно оценивают слова, не подтвержденные действием. Пословицы Del dicho al hecho hay much trecho [Glazer, c. 79] 'Oт слова к делу длинный nyть'; Del dicho al hecho hay gran trecho [Там же] - 'От слова до дела великий путь'; Buenas palabras no hacen buen caldo [Vitman, c. 15] - 'Хорошие слова не варят горячий бульон' иллюстрируют негативное отношение к речи, не подкрепленной действием. Использование ассоциаций с путешествием (длинный, долгий путь) отражает бытовую реальность мексиканцев. Мексиканские паремии не используют метафоры с основой пусто, как русские и американские паремии. Прагматическое совпадение оценки речевой ситуации имеет универсальный характер, является общечеловеческим. Когнитивное выражение универсальной ситуации различается, так как обуславливается национальной культурой. Каждый народ использует элементы быта, истории и культуры для выражения основных понятий мировосприятия.

Сопоставительный анализ паремий, выражающих концепт «Язык - Речь» в русском, американском английском и мексиканском испанском языках позволяет выделить универсальные, общечеловеческие категории. Мы утверждаем, что носители всех трех рассматриваемых языков ценят содержательную речь, умение свободно излагать мысли и обмениваться информацией. Национальная уникальность отражается в отношении к речевым ситуациям, предлагаемым моделям действий в них. Русские паремии акцентируют важность образной, свободной, «красивой» речи. Американцы так же отмечают важность свободной коммуникации, но при этом отдают предпочтение содержательной, краткой, «практичной» речи. Мексиканские пословицы подтверждают важность содержательной речи, однако для мексиканцев предпочтительнее молчание, которое предлагается как наиболее безопасное речевое поведение.

Язык изучается как один из важных способов формирования знаний об окружающем мире, именно язык является средством интерпретации действительности. Таким образом, можно утверждать, что современное языкознание изучает речевую деятельность, исследует взаимосвязь языка и речи. Благодаря языку и через речь человек познает окружающий мир, процессы концептуализации мира и систематизации полученных знаний уникальны для каждого народа. Паремии являются трансляторами константного языкового сознания как объекты утверждения, как проверенная временем общая истина. Паремии выражают национальную систему ценностей, мораль и языковое сознание нации, пословицы функционируют как позитивные и социальнопризнанные модели поведения. Паремиологический материал иллюстрирует коллективный исторический опыт народа, его уникальную культуру, выраженную в языке и отразившуюся в речевой деятельности. Модальной константой паремии является её безусловная истинность, которая доказана авторитетом народного мнения.

\section{Список литературы}

Аникин В. П. Русские пословицы и поговорки: Сборник / Под. ред. А. П. Аникина. М. : Художественная литература, 1988. $431 \mathrm{c.}$

Буслаев Ф. И. Исторические очерки русской народной словесности и искусства. СПб.: Общественная польза, 1861. 662 с.

Гальперин П. Я., Кабанова О. Я. Языковое сознание как основа формирования речи на иностранном языке // Управление познавательной деятельностью учащихся / Под ред. П. Я. Гальперина, Н. Ф. Талызиной. М. : МГУ, 1972. 260 с.

Гумбольдт В. Лаций и Эллада // Избранные труды по языкознанию. М. : Прогресс, 1984. С. 303-307.

Гумбольдт В. О различии строения человеческих языков и его влиянии на духовное развитие человеческого рода // Избранные труды по языкознанию. М. : Прогресс, 1984. С. 37-300.

Даль В. И. Пословицы русского народа. М. : Издательство АСТ, 2003. $736 \mathrm{c.}$

Жуков В.П. Словарь русских пословиц и поговорок. М. : Рус.яз., 2007. 649 с.

Зимин В. И. Словарь-тезаурус русских пословиц, поговорок и метких выражений. М. : АСТ-ПРЕСС, $2010.736 \mathrm{c}$.

Нечаева Е. Ф. Языковое сознание и национальный менталитет (к вопросу о терминологии) // Вестник ВГУ. Серия: Лингвистика и межкультурная коммуникация. Воронеж. : ВГУ, 2009. № 2. С. 30-33.

Пермяков Г. Л. Избранные пословицы и поговорки народов Востока. М. : Наука, 1968. 671 с.

Потебня А. А. Мысль и язык. Одесса.: Гос. издательство Украины, 1992. 205 с.

Сепир Э. Избранные труды по языкознанию и культурологии. М. : Прогресс, 1993. 656 с. 
Снегирёв И. М. Русские народные пословицы и притчи. М.: Институт русской цивилизации, 2014. $519 \mathrm{c}$.

Arora S.L. The Perception of Proverbiality // Wise Words. Essay on the Proverbs / Ed. by W. Mieder. New York. 1994. Pp. 3-29.

Fergusson R. The Penguin Dictionary of Proverbs. New York.: Penguin Group, 1983. 331 p.

Glazer M. A Dictionary of Mexican American Proverbs. Rio Grande.: Greenwood Press. 1987. 347 p.

Gómez de Silva $G$. Diccionario breve de Mexicanismos. México.: Academia Mexicana. 2000. $234 \mathrm{p}$.

Junceda L. Diccionario de refranes, dichos y proverbios. Madrid.: Espasa Calpe, 2009. 750 p.

Lane A. The Penguin Dictionary of Proverbs. London.: Penguin Group, 1983. 331 p.

Mieder $W$. A Dictionary of American Proverbs. New York.: Oxford University Press. 1992. 656 p.

Pérez- Martínez H. Refranero mexicano. México.: Academia Mexicana. 2004. 459 p.

Torres J.A. Al buen entendedor // Breve antología del refrán. México.: Quarzo. 2005. 117 p.

Vitman S.A. El Libro de Todos los Refranes. México.: Galaxia del Libro. 2008. 96 p.

\section{References}

Anikin, V. P. (1988). Russkie poslovitsy i pogovorki: Sbornik. Pod. red. A. P. Anikina [Russian Proverbs: A Collection of Works. Ed. by V. P Anikin]. 431 p. Moscow, Hudozhestvennaia literatura. (In Russian)

Arora, S. L. (1994). The Perception of Proverbiality. Wise Words. Essay on the Proverbs. Ed. by W. Mieder. New York. Pp. 3-29. (In English)

Buslaev, F. I. (1861). Istoricheskie ocherki russkoj narodnoj slovesnosti $i$ iskusstva [Historical Essays on Folk Literature and Art]. 662 p. Saint Petersburg, Public Benefit. (In Russian)

Dal', V. I. (2003). Poslovitsy russkogo naroda [Proverbs of Russian People]. 736 p. Moscow, izdatel'stvo AST. (In Russian)

Fergusson, R. (1983). The Penguin Dictionary of Proverbs. 331 p. New York, Penguin Group. (In English)

Gal'perin, P. Ia., Kabanova, O. Ia. (1972). Iazykovoe soznanie kak osnova formirovaniia rechi na inostrannom iazyke. Upravlenie poznavatel'noi dejatel'nost'iu uchashhihsia. [Linguistic Consciousness as the Basis for the Formation of Speech in a Foreign Language. Management of Cognitive Activity of Students]. Ed. by P. Ia. Galperin, N. F. Talyzina. 111 p. Moscow, MGU. (In Russian)
Glazer, M. (1987). A Dictionary of Mexican American Proverbs. 347 p. Rio Grande, Greenwood Press. (In English)

Gómez de Silva, G. (2000). Diccionario breve de Mexicanismos [Brief Dictionary of Mexicanismos]. 234 p. México, Academia Mexicana. (In Spanish)

Gumbol'dt, V. (1984). Latsii i Jellada [Latium und Hellas]. Izbrannye trudy po iazykoznaniiu. Pp. 303-307. Moscow, Progress. (In Russian)

Gumbol'dt, V. (1984). O razlichii stroeniia chelovecheskih iazykov $i$ ego vliianii na duhovnoe razvitie chelovecheskogo roda [On the Diversity of Human Language Construction and Its Influence on the Mental Development of the Human Species]. Izbrannye trudy po iazykoznaniiu. Pp. 37-300. Moscow, Progress. (In Russian)

Junceda, L. (2009). Diccionario de refranes, dichos y proverbios [Dictionary of Sayings and Proverbs]. 750 p. Madrid, Espasa Calpe. (In Spanish)

Lane, A. (1983). The Penguin Dictionary of Proverbs. 331 p. London. Penguin Group. (In English)

Mieder, W. (1992). A Dictionary of American Proverbs. 656 p. New York. Oxford University Press. (In English)

Nechaeva, E. F. (2009). Iazykovoe soznanie $i$ natsional'nyi mentalitet ( $k$ voprosu o terminologii) [Linguistic Consciousness and National Mentality (on the issue of terminology)]. Vestnik VGU. Seriia: Lingvistika i mezhkul'turnaia kommunikatsiia. Voronezh, VGU, No. 2, pp. 30-33. (In Russian)

Pérez-Martínez, H. (2004). Refranero mexicano [A Mexican Proverb]. 459 p. México, Academia Mexicana. (In Spanish)

Potebnia A. A. (1992). Mysl' $i$ iazyk [Thought and Language]. 205 p. Odessa. Gos. izdatel'stvo Ukrainy. (In Russian)

Sepir, Je. (1993). Izbrannye trudy po iazykoznaniiu $i$ kul'turologii. [Selected Works on Linguistics and Cultural Studies]. 656 p. Moscow, Progress. (In Russian)

Torres, J. A. (2005). Al buen entendedor. Breve antología del refrán. 117 p. México, Quarzo. (In Spanish)

Vitman, S. A. (2008). El Libro de Todos los Refranes. 96 p. México, Galaxia del Libro. (In Spanish)

Zimin, V. I. (2010). Slovar'-tezaurus russkih poslovits, pogovorok $i$ metkih vyrazhenii [DictionaryThesaurus of Russian Proverbs and Idioms]. 736 p. Moscow, AST-PRESS. (In Russian)

Zhukov V. P. (2007). Slovar' russkih poslovits $i$ pogovorok [Dictionary of Russian Proverbs]. 649 p. Moscow, Rus. iaz. (In Russian)

The article was submitted on 26.08.2019

Поступила в редакцию 26.08.2019

\section{Caserta Lilia Fidarisovna,}

Adjunct Professor,

Ferris State University,

829 Campus drive, Big Rapids,

MI 49307, USA.

casertal@ferris.edu 